\title{
Aviation and the environment: Rating airlines on their $\mathrm{CO}_{2}$ efficiency
}

\author{
Niels van Dorland ${ }^{1}$ and Frank van der Zwan ${ }^{2}$ \\ Delft University of Technology, 2629 HS Delft, The Netherlands \\ Stefaan Ghijs ${ }^{3}$ and Sicco Santema ${ }^{4}$ \\ Delft University of Technology, 2629 HS Delft, The Netherlands \\ and \\ Richard Curran ${ }^{5}$ \\ Delft University of Technology, 2629 HS Delft, The Netherlands
}

\begin{abstract}
The aviation industry contributes about $2 \%$ to the total global manmade $\mathrm{CO}_{2}$ emissions, which is seen as the main (manmade) greenhouse gas inducing climate change. This paper focuses on the design of a $\mathrm{CO}_{2}$ rating system which makes it possible to make a fair comparison of the environmental performance of airlines with respect to $\mathrm{CO}_{2}$ on the basis of public available data. It is argued that airlines can be best compared on the amount of $\mathrm{CO}_{2}$ emitted per revenue ton kilometer $\left(\mathrm{CO}_{2} / \mathrm{RTK}\right)$ on the basis of distance sectors. Therefore, an airline is rated on various distance sectors. The $\mathrm{CO}_{2}$ efficiency scores of an airline within a distance sector can then be compared with other airlines. For nine airlines the $\mathrm{CO}_{2}$ efficiency is modeled, and the distance sector boundaries are determined. It is shown that the relative positions of airlines may change when choosing a different boundary, since the $\mathrm{CO}_{2}$ efficiency changes with distance. It is also shown that on the basis of public available information it is difficult to accurately determine the $\mathrm{CO}_{2} / \mathrm{RTK}$ of an airline, which is due to lack of detail in public available data. A sensitivity analysis has been performed to show on which parameters information in greater detail is needed.
\end{abstract}

\section{Introduction}

$\mathrm{C}$ LIMATE CHANGE is a "hot" topic nowadays. The average Earth surface temperature is increasing due to human activities. Carbon dioxide $\left(\mathrm{CO}_{2}\right)$ is seen as the main manmade greenhouse gas which induces climate change, and it is emitted in almost every industry, including aviation. Although aviation only contributes $2 \%$ to the global man made $\mathrm{CO}_{2}$ emissions ${ }^{1}$, this share is expected to increase due to the rapid growth of the aviation industry. Besides $\mathrm{CO}_{2}$, there are other greenhouse gases emitted by aviation which induce climate change. In addition, aviation also has other environmental concerns such as noise and local air quality issues around airports.

\footnotetext{
${ }^{1}$ MSc student, Air Transport \& Operations, Faculty of Aerospace Engineering, Delft University of Technology, PO Box 5058, 2600 GB Delft, The Netherlands.

${ }^{2}$ Assistant professor, Air Transport \& Operations, Faculty of Aerospace Engineering, Delft University of Technology, PO Box 5058, 2600 GB Delft, The Netherlands, AIAA member.

${ }^{3}$ Airline project manager, Air Transport \& Operations, Faculty of Aerospace Engineering, Delft University of Technology, PO Box 5058, 2600 GB Delft, The Netherlands.

${ }^{4}$ Professor, Air Transport \& Operations, Faculty of Aerospace Engineering, Delft University of Technology, PO Box 5058, 2600 GB Delft, The Netherlands.

${ }^{5}$ Chair, Air Transport \& Operations, Faculty of Aerospace Engineering, Delft University of Technology, PO Box 5058, 2600 GB Delft, The Netherlands, AIAA Senior member.

1

American Institute of Aeronautics and Astronautics
} 
On most white good consumer appliances the performance in terms of energy use can be compared. All cars in the European Union (EU) are nowadays rated for their $\mathrm{CO}_{2}$ emission per kilometer. Further, financial institutes are rated for their creditworthiness by companies such as Standard \& Poor's. For aviation however, there is no rating which makes it possible to compare the environmental performance of airlines in terms of $\mathrm{CO}_{2}$ efficiency. In this paper, a rating methodology will therefore be designed. Although it is noticed that beside $\mathrm{CO}_{2}$ emission there are other environmental concerns, this paper will focus on $\mathrm{CO}_{2}$.

The main research question is defined as: "How is it possible to indicate how well or how bad an airline scores with respect to other airlines on their $\mathrm{CO}_{2}$ efficiency on the basis of public available parameters/data in order to make a justified comparison of airlines (a rating) and to give an initial advice to airlines for areas of improvement?" In addition, to evaluate whether a rating which only rates on $\mathrm{CO}_{2}$ emission covers 'aviation and environment', a concise literature review is presented about the effects of aviation on the environment.

\section{A. Environmental Concerns Aviation}

Besides $\mathrm{CO}_{2}$ there are various other environmental concerns relating to aviation: aircraft noise, local air quality, and global emissions (climate change) ${ }^{2}$. Aircraft noise is a subjective matter and is difficult to measure, i.e. one person may perceive aircraft noise as nuisance whereas another doesn't.

Local air quality (LAQ) is about the air quality at and around airports, and primarily relates to human health and welfare $^{2}$. The International Civil Aviation Organization (ICAO) has regulated the emissions from engines during the so-called landing and take-off cycle (LTO) which includes the operations below $3000 \mathrm{ft}$. Engine manufacturers have to comply with standards set by ICAO. Apart from the emissions from aircraft, the LAQ also includes emissions which are due to ground supporting activities, auxiliary power unit (APU) usage, and ground transport at or near airports ${ }^{2}$.

Climate change is caused by the emission of greenhouse gases (GHGs). Due to these GHGs the composition of the atmosphere changes and this affects the warmth balance of the Earth. By the combustion of fuel, various products are formed dependent on the completeness of the reaction: $\mathrm{CO}_{2}, \mathrm{NO}_{\mathrm{x}}, \mathrm{H}_{2} \mathrm{O}, \mathrm{SO}_{2}$, and soot ${ }^{1}$. Due to chemical reactions with substances in the atmosphere and microphysics, these substances change the radiative active substances in the atmosphere and therefore the radiative forcing, i.e. $\mathrm{CO}_{2}$, ozone, methane, $\mathrm{N}_{2} \mathrm{O}, \mathrm{H}_{2} \mathrm{O}$, aerosols and clouds ${ }^{1}$. Radiative forcing (RF) is defined as the global, annual mean radiative imbalance to the Earth's climate system caused by human activities ${ }^{1}$. The radiative forcing index (RFI) is used to express the perturbation of a substance to the atmosphere with respect to the radiative forcing of $\mathrm{CO}_{2}$ alone. On the whole, the aircraft emissions cause the Earth's surface temperature to increase. The quantities of the pollutants emitted by aircraft are solely dependent on the fuel consumption for $\mathrm{CO}_{2}$ and $\mathrm{H}_{2} \mathrm{O}$, i.e. for $\mathrm{CO}_{2}$ the mass of combustion product per unit mass of fuel is $3.15^{3}$. Further, the effect of emitting one ton of $\mathrm{CO}_{2}$ at ground level is the same as in the air ${ }^{1}$. For other pollutants, the impact on climate change depends on amongst others the altitude where it is emitted.

The other pollutants emitted by engines are dependent on the equivalence ratio $\Phi$ which is used to indicate the fuel-air mixture, i.e. lean, stoichiometric, and $\operatorname{rich}^{3}$. Therefore the quantity emitted by the engines is dependent on the thrust setting. Further, the level of scientific understanding of the radiative forcing of these substances is fair or poor ${ }^{4}$, i.e. for cirrus clouds which develop after the formation of contrails the scientific understanding is poor. Only for $\mathrm{CO} 2$ emission the scientific level of understanding is good. When considering the RFI index of Sausen et al. ${ }^{4}$, the total radiative forcing is about 1.9 as high (excluding cirrus) as the $\mathrm{RF}$ of $\mathrm{CO}_{2}$. Including non- $\mathrm{CO}_{2}$ emissions could be done by using a multiplier such as RFI to account for the non- $\mathrm{CO}_{2}$ emissions. Other metrics that could be used to calculate the effect of the individual substances on radiative forcing are Global Warming Potential and Global Temperature Potential. However, RFI as well as the aforementioned metrics are not directly applicable to aviation $^{5}$, and proper methods should be established by further research ${ }^{6}$.

There are trade-offs between the environmental issues, i.e. decreasing $\mathrm{CO}_{2}$ emission of an engine may increase the $\mathrm{NO}_{\mathrm{x}}$ emissions. Further, more silent engines can be heavier, and therefore may result in a higher $\mathrm{CO}_{2} \mathrm{emission}^{7}$. Therefore for a rating, using a multiplier to include non- $\mathrm{CO}_{2}$ emission may result in distortion.

From this literature review it can be concluded that besides $\mathrm{CO}_{2}$ emission, other environmental issues are linked to aviation. Rating only on $\mathrm{CO}_{2}$ will thus not cover 'aviation and environment'. As was mentioned in the introduction, the scope of this research is on the $\mathrm{CO}_{2}$ emission of an airline. The $\mathrm{CO}_{2}$ emission of an airline can be divided into $\mathrm{CO}_{2}$ emission due to ground supporting activities (catering, fuel vehicles etc.) and air operations (caused by the power source of the aircraft itself). It has been decided to scope on the $\mathrm{CO}_{2}$ emissions caused by air operating activities, which covers the fuel used by the power source of the aircraft, i.e. the engines and APU. To put this into perspective, $99 \%$ of the total $\mathrm{CO}_{2}$ emission was due to air operation activities for Air France/KLM ${ }^{8}$ in $2007 / 2008$ and only $1 \%$ for ground operations. 


\section{B. Existing Ratings}

There are various ratings on the market which compare the performance of products or companies. In analogy with these existing ratings, the airline rating methodology can be set-up. Therefore we have explored how existing ratings rate 'white goods', cars, aircraft, and companies.

The EU energy label gives 'white goods' a class score (A-G) to indicate the performance of a product. For consumer goods, the energy efficiency of a product is typically the metric used for comparison. The energy efficiency metric for a washing machine has been defined as the energy use (in $\mathrm{kWh}$ ) $\mathrm{kg}$ washing load. The washing load has been included in the metric because there are washing machines with different loading sizes. Excluding the latter would make small washing machines in general more energy efficient. Further, to measure the energy consumption and make a comparison possible, a standard washing program has been defined by the $\mathrm{EU}^{9}$. To reduce the $\mathrm{CO}_{2}$ emitted by cars and to reach the GHG reduction target agreed upon by the EU at the Kyoto conference in 1997, the EU decided to label cars for their $\mathrm{CO}_{2}$ emission. The metric used in the rating is gram $\mathrm{CO}_{2}$ emission per kilometre.

Flybe, a UK regional airline, has developed a methodology to compare the environmental performance of aircraft ${ }^{10}$. They rate aircraft separately on three aspects: noise, $\mathrm{LTO} \mathrm{CO}_{2}$ emission, and journey $\mathrm{CO}_{2}$ emission. For the noise rating, they use the average quota count of an aircraft for departure and arrival. The $\mathrm{LTO} \mathrm{CO}_{2}$ emission is based on the absolute $\mathrm{CO}_{2}$ emission, and for the journey $\mathrm{CO}_{2}$ emission they rate aircraft on both absolute $\mathrm{CO}_{2}$ emission as well as $\mathrm{CO}_{2}$ emission per seat. Furthermore, they rate aircraft on several distances in order to compare aircraft which serve the same routes with each other. Since an aircraft has a certain range, it is rated only at distances on which it can operate. Flybe assigns a rating score (A-G) by determining the best and worst performer of a distance (in terms of $\mathrm{CO}_{2}$ per seat or absolute $\mathrm{CO}_{2}$ emission) and dividing the difference between six equal bands.

DeCicco and Thomas ${ }^{11}$ designed a "Green Rating" for cars which considers elements of the life cycle of a car. For the various car emissions, the cost to the environment has been established (i.e. dollar/gram of emission), and an environmental damage cost index has been used to calculate the impact of emissions on environment Due to lack of data and resources, DeCicco and Thomas focused on the use-phases energy and air pollution effects for the material production, product manufacture and product use phase ${ }^{11}$. Because multiple environmental issues were taken into account, DeCicco and Thomas gave equal importance to the impacts of GHG emissions as to health-related pollution for a typical $\mathrm{car}^{11}$.

Standard \& Poor's (S\&P's) give their opinion on the capacity and willingness of a company to meet its financial commitments on time ${ }^{12}$. Both quantitative and qualitative factors are used by S\&P's to form an opinion on the credit risk. Each company has a business risk- and a financial risk profile from which a rating score is determined. The rating is forward looking, which means that S\&P's also considers market trends and take into account the business cycle. When a company is active in different segments, each segment is analyzed separately, followed by an analysis of how important each segment is to the overall organization, and is weighted accordingly ${ }^{12}$.

\section{Methodology Approach}

In analogy with existing ratings, a $\mathrm{CO}_{2}$ airline rating will be set-up. Therefore a metric for the $\mathrm{CO}_{2}$ efficiency is determined. Further it is decided how to compare airlines in a justified way. When a metric has been defined and it has been chosen how to rate airlines, the $\mathrm{CO}_{2}$ efficiency of several airlines (i.e. network, regional and low cost carrier) will be calculated. This is done by making a model which includes all flight phases in order to estimate the $\mathrm{CO}_{2}$ emission of an airline. This model is made on the basis of public available sources.

Since no actual fuel data of airlines is used, assumptions are made which will affect the accuracy of the rating. For each phase/parameter the range in which it typically varies are determined (on the basis of public available information), and a base value is chosen. Further, to evaluate the $\mathrm{CO}_{2}$ emission model, a validation is performed on actual airline U.S. BTS data ${ }^{13}$. This will give insight in how well the model estimates the $\mathrm{CO}_{2}$ emission of an airline. In order to determine which parameters need to be known most accurately for a $\mathrm{CO}_{2}$ rating a sensitivity analysis is performed. From this analysis, together with defined ranges, it can be shown on which parameters the focus should be for rating accuracy improvement.

By analyzing several airline types, differences in $\mathrm{CO}_{2}$ efficiency between airlines may be observed, and it may be possible to group airlines and give them a class score, such as A, B, C etc.

\section{Building the model}

In this section a $\mathrm{CO}_{2}$ efficiency metric is defined, followed by a discussion of how to rate airlines. Finally, the airline fuel modeling for the different stages of the landing and take-off (LTO) cycle is determined. 


\section{A. Fuel Efficiency / $\mathrm{CO}_{2}$ efficiency metric}

Since the $\mathrm{CO}_{2}$ emission from an airline is directly related to the fuel consumption, the $\mathrm{CO}_{2}$ efficiency equals the fuel efficiency (multiplied by a constant factor). IPCC $^{1}$ defines transportation efficiency as the fuel required to transport one person over a distance of 1 kilometre-the energy required per passenger-km. Further they mention that freight may be compared on the basis of energy use per ton-km . Mak et al. ${ }^{14}$ compared the environmental reports of airlines and found differences in the fuel efficiency definition that airlines use. It is found that the common definition used for fuel efficiency is the fuel used per passenger distance or fuel per RPK. However, also fuel per RTK (revenue ton kilometer) and fuel per ASK (available seat kilometer) are used by airlines. The fuel efficiency definition depends on whether one wants to compare passenger or freight transport. When rating on fuel per ASK the fact that besides passenger also cargo can be transported is neglected. Further it does not take into account how airlines use their capacity. Fuel over RPK takes into account how airlines use their seat capacity, however again neglects cargo transport. Although there are airlines such as low cost carriers that only transport passengers, network carriers usually transport both, i.e. in the belly hold of a passenger aircraft it can carry freight.

To include both passengers and cargo transport in a metric, the fuel efficiency is defined as the fuel required to transport revenue weight (cargo as well as passengers) over a distance unit, i.e. $\mathrm{CO}_{2} / \mathrm{RTK}$. A typical weight should then be assigned to a passenger (including baggage). When rating on $\mathrm{CO}_{2} / \mathrm{RTK}$, airlines are rated on how efficient they use their transport output, i.e. how well do they use their available capacity in terms of both passenger and cargo transport. RTK is commonly used in the aviation industry as a measure of the transport output.

\section{B. Comparing Airlines on their $\mathrm{CO}_{2}$ Efficiency}

In the Flybe aircraft rating, aircraft are rated on several distances on which they operate. This makes it possible to compare aircraft that operate on the same (fixed) distances. In analogy with this, an airline could also be rated on fixed distances. However comparing airlines is more complex since an airline is composed out of aircraft types that are put on several routes, for which the $\mathrm{CO}_{2}$ efficiency differs per route and aircraft. Although one particular aircraft of an airline may be very efficient, the $\mathrm{CO}_{2}$ airline rating should rate the total $\mathrm{CO}_{2}$ efficiency of an airline and how it uses its fleet. Therefore, it could be decided to determine the $\mathrm{CO}_{2}$ efficiency by dividing the total $\mathrm{CO}_{2}$ emission and RTK production of an airline. However, is it fair to compare airlines that operate on totally different hauls? Could a regional carrier's $\mathrm{CO}_{2}$ efficiency score be compared with one of a network carrier? Since in general the efficiency in terms of fuel per km increases with distance, a regional carrier might by definition be less efficient than a network carrier. The $\mathrm{CO}_{2} / \mathrm{RTK}$ score of a network carrier is predominantly determined by its long haul flights. For example, for one of the analyzed airlines the shares of $\mathrm{CO}_{2}$ emission and RTKs with respect to the airline's total are respectively $85 \%$ and $92 \%$ for flights above 1,500 kilometers, whereas they cover only $23 \%$ of the airline's total flights. This means that an airline's $\mathrm{CO}_{2} / \mathrm{RTK}$ score is predominantly determined by its flight above $1,500 \mathrm{~km}$ in this example. Whereas the $\mathrm{CO}_{2}$ efficiency of the regional flights of this carrier are very $\mathrm{CO} 2$ inefficient has no significant effect on the rating score. Therefore when rating airlines on $\mathrm{CO}_{2} / \mathrm{RTK}$ in this way, the $\mathrm{CO}_{2}$ efficiency cannot be compared in a justifiable way.

One could argue that the $\mathrm{CO}_{2} / \mathrm{RTK}$ could be calculated per flight, and then that the overall score would be determined by adding up all single scores and divide it by the total number of flights. However, in that case the airline in the example would be predominantly rated on its flights below 1,500 km since it performs $77 \%$ of its flights in that sector. Therefore, another approach should be followed to make a justified comparison between airlines.

One could see an airline as a composition of various 'products', i.e. the transport of payload on regional haul routes, short haul routes etc. An airline decides which aircraft they put on its routes, which can be based on various reasons which are beyond the scope of this research. When comparing the $\mathrm{CO}_{2} / \mathrm{RTK}$ on so-called distance sectors, the same sort of 'products' are compared, i.e. the regional network of a network carrier would be compared with a regional carrier. Whether an airline uses an aircraft which is designed for long haul or puts 130 seats instead of 150 seats in an aircraft to accommodate business passengers is their choice. For the rating only the $\mathrm{CO}_{2} / \mathrm{RTK}$ matters which considers how an airline performs in a sector. How the distance sectors will be defined will be determined later in the analysis. It should be noted that when an airline is rated in a distance sector it does not mean that all flights of that airline are less/more $\mathrm{CO}_{2}$ efficient than these other airlines. 
Concluding, the approach for which it is believed that a justified comparison can be made is to rate an airline on $\mathrm{CO}_{2}$ / RTK on several distance sectors. This approach is illustrated in Fig. 1, which shows seven airlines operating in various distance sectors. An airline will only be rated when it is operating in a distance sector. The number of distance sectors and the position of the boundaries will be discussed later.

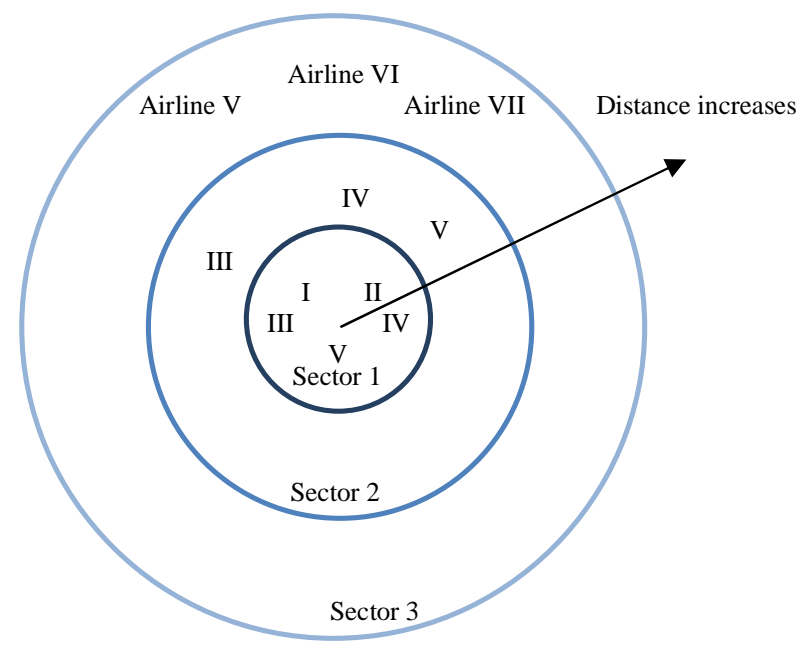

Figure 1. Rating airlines on distance sectors on their $\mathrm{CO}_{2} / \mathrm{RTK}$

\section{Airline Fuel Modeling}

Since the scope is on $\mathrm{CO}_{2}$ emitted during the air operation activities, the $\mathrm{CO}_{2}$ emission of an airline from the engine as well as the APU needs to be determined. When the $\mathrm{CO}_{2}$ emission and RTKs of an airline are known, the efficiency can be calculated.

Similar to existing emission models (such as AEM3 by Eurocontrol ${ }^{15}$ ), the fuel of a flight is composed out of two components: the LTO cycle fuel (below 3,000 ft), and the climb/cruise/descent fuel (above 3,000 ft). The LTO cycle comprises the following phases: taxi-out, take-off, climb-out, descent/landing, and taxi-in. Apart from these phases, the parking phase has been added in order to account for the fuel used by the APU. Figure 2 shows an illustration of the phases included in the model.

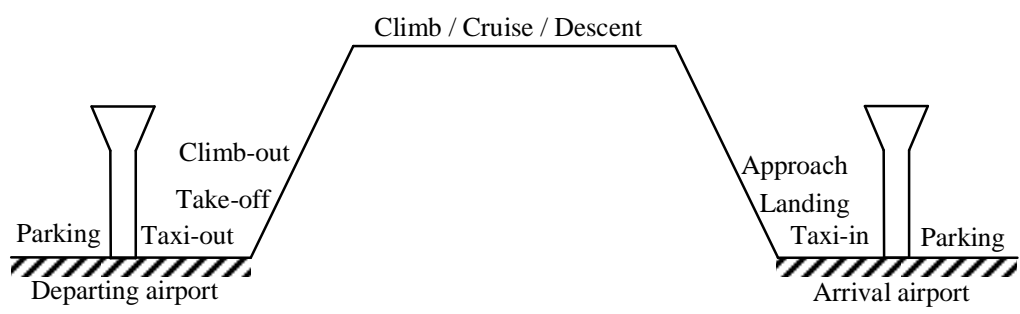

Figure 2. Flight phases considered in the model

For all of these flight phases the parameters affecting the fuel of the phases have been investigated. Although each phase basically depends on thrust setting and duration, the relation between these two is not well known, i.e. a lower thrust setting may result in a longer duration which could mean a reduced $\mathrm{CO}_{2}$ emission, however also the opposite. Therefore it was decided to set for each phase (excluding climb/cruise/descent) a standard thrust setting and duration, which is referred to as base values. The typical range in which the fuel varies for a phase with respect to the fuel calculated by using the base values was then determined. This could then be used in a sensitivity analysis to show whether a phase or parameter was needed in more detail or not, i.e. when a change in parameter only has a minor effect on the rating output, then using a base value may suffice. It is further used to get insight on what parameters the focus needs to be for further research. 


\section{LTO phases}

For the LTO cycle standards defined by ICAO have been used for thrust setting and duration. This means that for each engine, the fuel flow has been used as filed in the ICAO Engine Emissions Databank ${ }^{16}$, which is based on the defined thrust setting. Eurocontrol ${ }^{15}$ have also used for their emission model the ICAO LTO thrust setting and durations, and validated it with actual airline data. From their results, the range in which the fuel varies (normalized) was determined.

\section{Parking phase}

For the parking phase, the duration and fuel flows of the APU were deduced from Unique ${ }^{17}$, which specifies for a number of aircraft type which APU type is typically used and the average fuel consumption per hour. When an aircraft is parked at a pier it only uses the APU for about 8 minutes (at Zurich Airport), however when at a remote stand it may use the APU for about 41 minutes. A ground power unit may also be used, however, from ASPIRE ${ }^{18}$ it was noted that some airports charge excessive fees for the use of these units. Some airports limit the duration of APU because of LAQ issues ${ }^{19}$, however for most airports it is known that they have not such restrictions. Therefore it was decided to use 41 minutes as base value for the APU duration. Further research is necessary whether this duration can be used on all aircraft types since Unique ${ }^{17}$ shows that there are significant differences between turboprop and short haul aircraft.

\section{Climb/cruise/descent phase}

For the climb/cruise/descent phase fuel flow data from the Emission Inventory Guidebook (EIG) ${ }^{20}$ was used, also referred to as EMEP/CORINAIR data. It gives the fuel consumption for 44 aircraft types on several distances, i.e. $125 \mathrm{~nm}, 250 \mathrm{~nm}$ etc., which are deduced from calculations by PIANO (Project Interactive Analysis and Optimization). Although the assumptions on which the calculations are based are not mentioned in EIG, it has been assumed that the fuel information represents optimal flight conditions, which are typically used in emission inventories, i.e. NASA ${ }^{21}$ mentions for their model: no winds, no cargo, optimal flight profile, optimal operating rules, direct distance etc.

Therefore, the fuel data of $\mathrm{EIG}^{20}$ cannot be directly used to estimate the $\mathrm{CO}_{2}$ emission of an airline. In the model the following aspects are corrected for: altitude, speed, payload weight, engine deterioration, centre of gravity position, and additional distance with respect to the great circle distance (GCD). Other aspects which influence the fuel consumption are weather conditions (wind), and temperature difference at altitude with respect to standard conditions, however are assumed to cancel out.

Airbus $^{22}$ analyzed the factors that affect the fuel consumption of aircraft. They investigated the effect of flying lower/higher than the optimal altitude for several aircraft. According to Airbus ${ }^{23}$, aircraft typically fly about $\pm 2,000 \mathrm{ft}$ near their optimum altitude, due to amongst others Air Traffic Control (ATC). Further, it should be noted that the optimum altitude is not fixed, i.e. the aircraft becomes lighter due to the burning of fuel and therefore has a different optimum altitude. This causes the fuel to increase by about $1-2 \%$. However flying at altitudes farther below or above the altitude will cause a fuel penalty higher than 2\%, i.e. an Airbus A320 which operates 4,000 ft below its optimal altitude will have a 5-6\% fuel penalty compared to optimal ${ }^{22}$. For the model it has been decided to correct the fuel used during the climb/cruise/descent phase by adding $2 \%$ of extra fuel to the total fuel consumption during this phase. It should be noted that this value should be investigated further, i.e. whether it may be applied on long haul flights as well as regional flights and whether there are differences between aircraft etc. From Airbus ${ }^{22}$ it can be deduced that there are differences in fuel penalty between aircraft types.

For the EIG (2007) fuel data it has been assumed that the speed at which an aircraft operates is the speed at which $99 \%$ of the specific air range can be achieved, also known as the long range cruise (LRC) speed. This assumption is commonly used in emission inventories such as $\mathrm{NASA}^{21}$ and AERO2 $\mathrm{K}^{24}$. The speed at which the minimum fuel is used is the maximum range cruise (MRC) speed. However, the time gain by using the LRC speed instead of the MRC speed is significant, and therefore airlines typically fly faster than the MRC speed. Since fuel costs are only part of the total operating cost of airlines, the so-called cost index (CI) is used to express the cost of time versus cost of fuel. Airlines use the CI to determine the speed which is most economical. This speed is different for each airline (due to a different cost structure), and might even differ per route ${ }^{25}$. The flight management system of an aircraft has a feature which allows a pilot to select a certain CI, from which the climb/cruise/descent speed is determined $^{25}$. For several Airbus aircraft Airbus ${ }^{23}$ determined the fuel increase using a typical cost structure of an airline. For the analyzed aircraft the fuel increase could be up to 7\% between the extremes, i.e. MRC and maximum operating speed. However neither extremes are used by airlines. Although it is expected that airlines operate at higher speed than MRC and LRC, it cannot be exactly quantified. It has been decided to add $1 \%$ of fuel due to speed to the EMEP/CORINAIR climb/cruise/descent fuel. 
The weight of the aircraft influences also the fuel consumption of an aircraft. Airbus ${ }^{22}$ found that increasing the maximum take-off weight by $1 \%$ will increase the fuel consumption of about $0.8-1.2 \%$, dependent on the aircraft type. Although operating empty weight differences between airline operators will cause the fuel consumption to vary, the largest weight differences will be in the traffic load weight, and in the fuel load carried. The fuel that an airline loads depend on the trip fuel needed to reach the destination plus contingency fuel for safety reasons and extra fuel. The latter can be added by the captain for various reasons, i.e. weather conditions, lack of confidence in flight planning etc. ${ }^{22}$. The traffic load consists of the weight of the revenue passengers and cargo. For the EMEP/CORINAIR data it is known that for the turboprops a passenger load factor (PLF) of $65 \%$ is used ${ }^{20}$. For the turbojets the PLF is not known, however as mentioned before emission inventory models typically use a 70\% PLF. This means that when using the EMEP/CORINAIR data in the model, the climb/cruise/descent fuel needs to be corrected for airlines that operate with a different PLF. The PLF only tells how much seats in an aircraft are occupied, however it does not tell how much of the payload capacity is used in an aircraft The weight load factor expresses that instead, which is defined as the ratio of the weight transported over the capacity available. The relation between the weight load factor (WLF) and fuel consumption was investigated by LIDO for University of Westminster $^{26}$. They analyzed the fuel flow differences between different WLF: $50 \%$, 65\%, and 80\%. On the basis of this research it has been calculated what the effect of a $1 \%$ increase in WLF is on the fuel consumption of an aircraft. It was found that the fuel consumption increase depends on the aircraft, i.e. the one aircraft has a higher payload capacity than the other. In general a $1 \%$ increase in WLF will cause the fuel consumption to increase between $0.18-0.32 \%$. This means that flying with a WLF of $0 \%$ instead of $100 \%$ will let the fuel consumption decrease by $18-32 \%$ dependent on the aircraft type.

A $65-70 \%$ PLF load factor of EMEP/CORINAIR does not directly tell how much of the payload capacity is used. For the model, it has been assumed that a PLF of $65-70 \%$ equals $50 \%$ of the WLF, and a relation was set-up to account for the additional weight of an airline compared to modeled by EMEP/CORINAIR.

Due to a misplaced centre of gravity $(\mathrm{CG})$ position the fuel consumption may also increase. Airbus ${ }^{22}$ analyzed for several Airbus aircraft types the difference in specific range due to an aft and forward CG. Since it is assumed that an airline will typically operate with a CG which is close to optimal, it has been assumed that due to CG an additional fuel quantity of $1 \%$ of the total fuel consumption is used.

In addition to the direct route or GCD between airports, excess distance is flown caused by amongst others: ATC, Standard Instrument Departures (SIDs), Standard Terminal Arrival Route, weather conditions and course reversals. Kettunen et al. ${ }^{27}$ suggests that the additional distance may vary between geographic regions. Faber et al. ${ }^{28}$ has calculated the mean excess distance for several distance sectors, which is used to correct the GCD between airports in the model.

Engine deterioration causes the fuel consumption to increase due to dirt accumulation, mechanical wear, and erosion $^{29}$. Eurocontrol ${ }^{30}$ mentions that on the basis of information provided by some airlines, the increase in fuel use due to engine deterioration is between $2-6 \%$. Based on $\mathrm{NASA}^{21}$, a logarithmic formula was derived to correct for the increase in fuel consumption due to engine deterioration.

The parking, LTO phase, and climb/cruise/descent phase have been used to calculate the fuel consumption in the model. For US carriers that report both fuel consumption and airline schedule data, the fuel consumption has been calculated using the model in order to see whether the estimation is close to actual reported fuel data. Although, the sample size is small, the objective is to verify whether the fuel estimation is close to actual. Differences can be explained due to assumptions and variations in the phases and parameters. Some of the results are shown in Table 1.

Table 1. Fuel calculation for several aircraft types of airlines.

For quarter 1 and 2 of the year 2008 (based on US BTS data)

\begin{tabular}{|l|l|l|}
\hline $\begin{array}{l}\text { Aircraft } \\
\text { types }\end{array}$ & $\begin{array}{l}\text { Calculated } \\
\text { vs. Real }\end{array}$ & $\begin{array}{l}\text { Rev a/c airborne hours / } \\
\text { total airborne hours }\end{array}$ \\
\hline A319 & 1.02 & 1.00 \\
\hline A320 & 0.98 & 1.00 \\
\hline A330 & 1.07 & 1.00 \\
\hline AT72 & 0.90 & 1.03 \\
\hline B733 & 1.06 & 1.00 \\
\hline B735 & 1.07 & 1.00 \\
\hline B737 & 1.10 & 1.00 \\
\hline B738 & 1.03 & 1.00 \\
\hline
\end{tabular}

\begin{tabular}{|l|l|l|}
\hline Aircraft types & $\begin{array}{l}\text { Calculated } \\
\text { vs. Real }\end{array}$ & $\begin{array}{l}\text { Rev a/c airborne } \\
\text { hours / total } \\
\text { airborne hours }\end{array}$ \\
\hline B742 & 0.95 & 0.96 \\
\hline B752 & 1.01 & 1.00 \\
\hline B753 & 1.04 & 1.00 \\
\hline B763 & 0.99 & 1.00 \\
\hline B772 & 1.04 & 1.00 \\
\hline DH8B & 1.46 & 0.99 \\
\hline DH8D & 1.27 & 0.99 \\
\hline MD82 & 1.01 & 1.00 \\
\hline
\end{tabular}

7

American Institute of Aeronautics and Astronautics 
The ratio of calculated vs. real is defined as the modeled fuel divided by the actual reported fuel of US carriers, i.e. when this ratio is 1 the calculated fuel equals the reported fuel. The revenue aircraft airborne hours over the total airborne hours indicates whether the schedule over which the fuel has been calculated is the fuel over which an airline has reported its data, i.e. 95 means that the fuel calculation is made on the basis of only $95 \%$ of the total flown hours for which the fuel is reported. From the results it cannot be deduced whether the fuel of phases have been determined correctly; only the total can be compared.

The results show that the fuel calculation reasonably equals the actual reported fuel consumption. The largest difference between calculated and actual fuel is in aircraft that operate on regional/short haul distances. This may indicate that the LTO fuel is overestimated since the share of LTO is greater for short flights. However, further research is necessary in order to adjust the model.

\section{Model $\mathrm{CO}_{2}$ Efficiency Airlines}

In order to calculate the $\mathrm{CO}_{2}$ efficiency of an airline one has to determine besides the $\mathrm{CO}_{2}$ emission the RTK production. The RTK production of an airline is dependent on the payload weight transported and the flown distance. Therefore an estimation about the payload needs to be made. Further in order to determine the $\mathrm{CO}_{2}$ efficiency of an airline, some airline specific parameters have to be set besides the general parameters (i.e. $\mathrm{CG}$, additional distance etc.) which were treated in the previous section. The $\mathrm{CO}_{2}$ efficiency of airlines will be determined on the basis of actual flight data (schedule, aircraft, frequency) provided by Eurocontrol. This data file contains all flights performed in January 2004. The use is however limited to flights only departing and arriving from European countries (ECAC), which means that flights outside this area are not included, i.e. a flight from Hong Kong to Sydney. However, it is not expected that this makes a significant difference in rating score.

When the $\mathrm{CO}_{2}$ efficiency of several airline types have been determined, the scores can be compared and the boundaries of the distance sectors will be determined. Since an answer needs to be found on whether airlines can be rated on the basis of public available data, the range in which each parameter varies has also been analyzed. Therefore, for each parameter/phase the range in which the fuel can vary has been determined. By a sensitivity analysis, the effect of these ranges on the rating output are analyzed. From the sensitivity analysis, it can then be seen which parameters need to be known more accurate to rate an airline on the basis of public available data. An overview of the model is shown in Fig. 3.

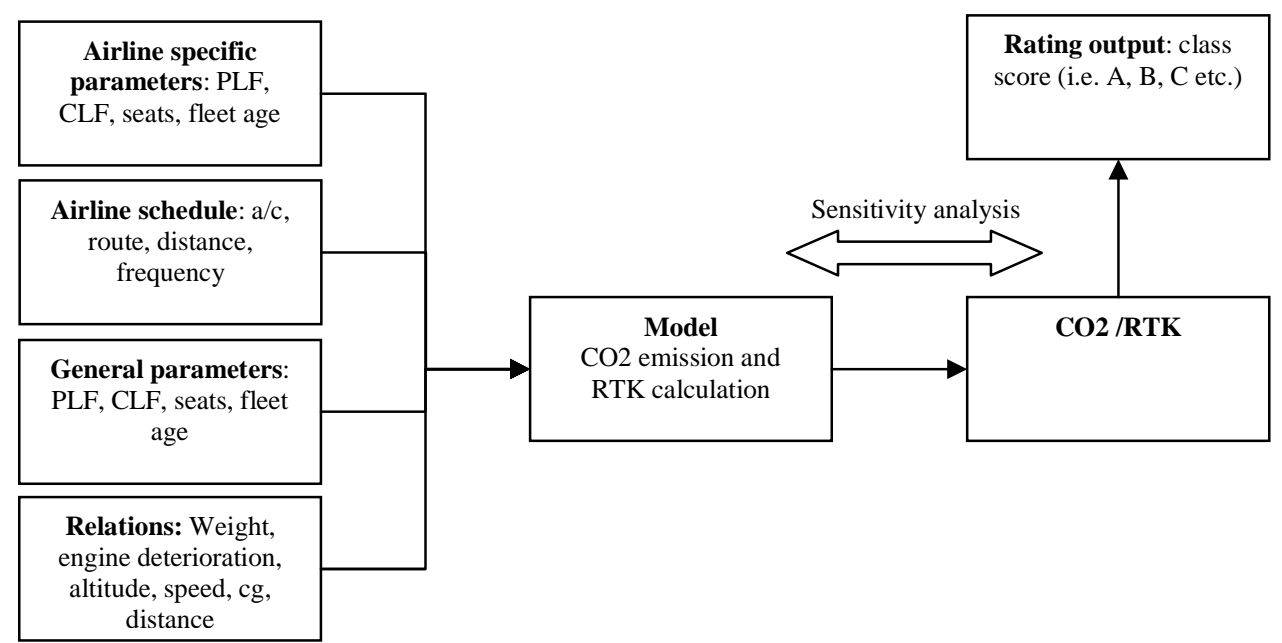

Figure 3. Overview of model which calculates the $\mathrm{CO}_{2}$ efficiency of airlines

For the analysis, in order to find differences in $\mathrm{CO}_{2}$ efficiency between different business types it was decided to select 3 low-cost carriers (LCCs), 3 network carriers (NWs), and 3 regional carriers (REGs), which are abbreviated as shown in Table 2. A low cost carrier is defined as a carrier with a high seating density and typically active on distances below about $2000 \mathrm{~km}$. A network carrier is active on all distances, from regional to ultra long haul. Further, a regional carrier is predominantly active on distances below about $1000 \mathrm{~km}$. 
Table 2. The airline types and names assigned to the airline cases

\begin{tabular}{|l|l|l|l|}
\hline Airline type & Airline name & Airline name & Airline name \\
\hline Network Carrier & NW1 & NW2 & NW3 \\
\hline Low Cost Carrier & LCC1 & LCC2 & LCC3 \\
\hline Regional Carrier & REG1 & REG2 & REG3 \\
\hline
\end{tabular}

\section{A. Airline specific parameters}

The PLFs for the airlines are derived from an IATA survey of 2008. The PLF information in the survey is either compiled out of IATA World Air Transport Statistics or out of airline annual reports. Since it was decided to rate airlines on certain distance sectors which are defined later, the PLF should be determined on these sectors. Using an annual PLF for an airline's total flight may result in inaccuracy in the rating. However, since airlines usually provide no PLF per distance and no specific information could be found about the PLF, the average annual PLF is used for all (to be defined) distance sectors.

Mainly network carriers transport besides passengers also cargo. However, the share of cargo transported is not well known. On the basis of US BTS ${ }^{13}$ data, the cargo load factors from/to US from the selected network carriers have been determined. For the three selected network carries the cargo load factor (CLF) varied between 20-30\%. Since this CLF may not be representative for all flights of a network carrier it has been decided to make a distinction between CLF for distances below 1,500 km (regional/short haul) and above 1,500 km. The CLF of all NWs have been set at $25 \%$ for flights with a distance larger than $1,500 \mathrm{~km}$. For flights below $1,500 \mathrm{~km}$, it has been decided to only use a 4\% CLF for network carriers, since the share of cargo is usually low for European routes. For REG carriers and LCC carriers no cargo has been taken into account.

The payload capacities of aircraft have been derived from US BTS data ${ }^{13}$. For each aircraft the available payload capacity of a passenger aircraft have been determined. The number of seats in an aircraft differs per airline, and might even differ within an airline for the same aircraft type. The number of seats of the analyzed airlines were taken from either the airline's website or seatguru.com ${ }^{31}$. In the case an aircraft type was no longer used by an airline, typical seating configurations for a carrier were used instead.

The fleet age have been used from airfleets.net ${ }^{32}$ which is a website for which from each airline the average weighted age can be obtained. Whether it is appropriate to use the average weighted fleet age to correct for engine deterioration should be investigated, i.e. the fleet age does not necessarily say something about the engine age, i.e. an airline could have replaced an engine in the meanwhile.

It should be mentioned that the accuracy of the airlines specific parameters is low. This is because airlines do not publish the data in the preferred detail. Further research is necessary in the airline specific parameters and the effect on the rating score. In order to see on which parameters the focus needs to be for data improvement, the typical or expected range in which a parameter varies and the effect on the rating output will be investigated using tornado diagrams. In the next section the model results will be discussed and the distance sectors will be defined.

\section{Results}

For each of the airlines the $\mathrm{CO}_{2}$ efficiency score has been determined. Before proceeding with the base-case results discussion, the distance boundaries needs to be determined as well as the number of sectors for which the $\mathrm{CO}_{2}$ efficiency needs to be calculated. The first distance sector will start at $0 \mathrm{~km}$, and the boundary of the distance sector on the right needs to be determined. Therefore the $\mathrm{CO}_{2} /$ RTK score of airlines have been calculated by increasing the right boundary from 0 to 2,000 km as shown in Fig. 4 below.

The reason why the $\mathrm{CO}_{2}$ / RTK score decreases is because the $\mathrm{CO}_{2}$ efficiency increases in general with increasing distance. This is because a flight that travels farther spends relatively more time in the fuel efficient cruise phase. Further the share of the LTO-cycle to the total decreases. From Figure 4, one can conclude that basically three groups of airlines are formed with about the same $\mathrm{CO}_{2}$ efficiency score: LCC1-3; NW1-3 and REG1,3; and REG1.

The choice of where to put the right boundary of distance sector 1 affects the relative position of airlines with each other, i.e. in the figure a cross means that the relative position of one carrier changes with the other. It can also be seen that for the regional carriers, the $\mathrm{CO}_{2}$ efficiency stays constant after about $1,000 \mathrm{~km}$. This due to that these carriers don't operate on these distances. This means that when putting the boundary at distances after $1,000 \mathrm{~km}$ the comparison becomes invalid. The boundary needs to be placed at a position in which still a comparison can be made, i.e. when all (or most) carriers perform flights in a distance sector. When one chooses the boundary below distances of about $500 \mathrm{~km}$, the relative position of airlines changes considerably. It has been decided to put the first 
distance sector at $750 \mathrm{~km}$, because the relative position of airlines changes not that much anymore. The first distance sector is thus defined as: $0-750 \mathrm{~km}$.

It should be noted that a change in rating score would not directly mean that the class score (i.e. A, B, C) differs. Therefore the way the rating score is mapped onto a class score may also be considered when choosing the boundary. The distance should be set at places where the least class score changes occur, and at such a place that a comparison can still be made.

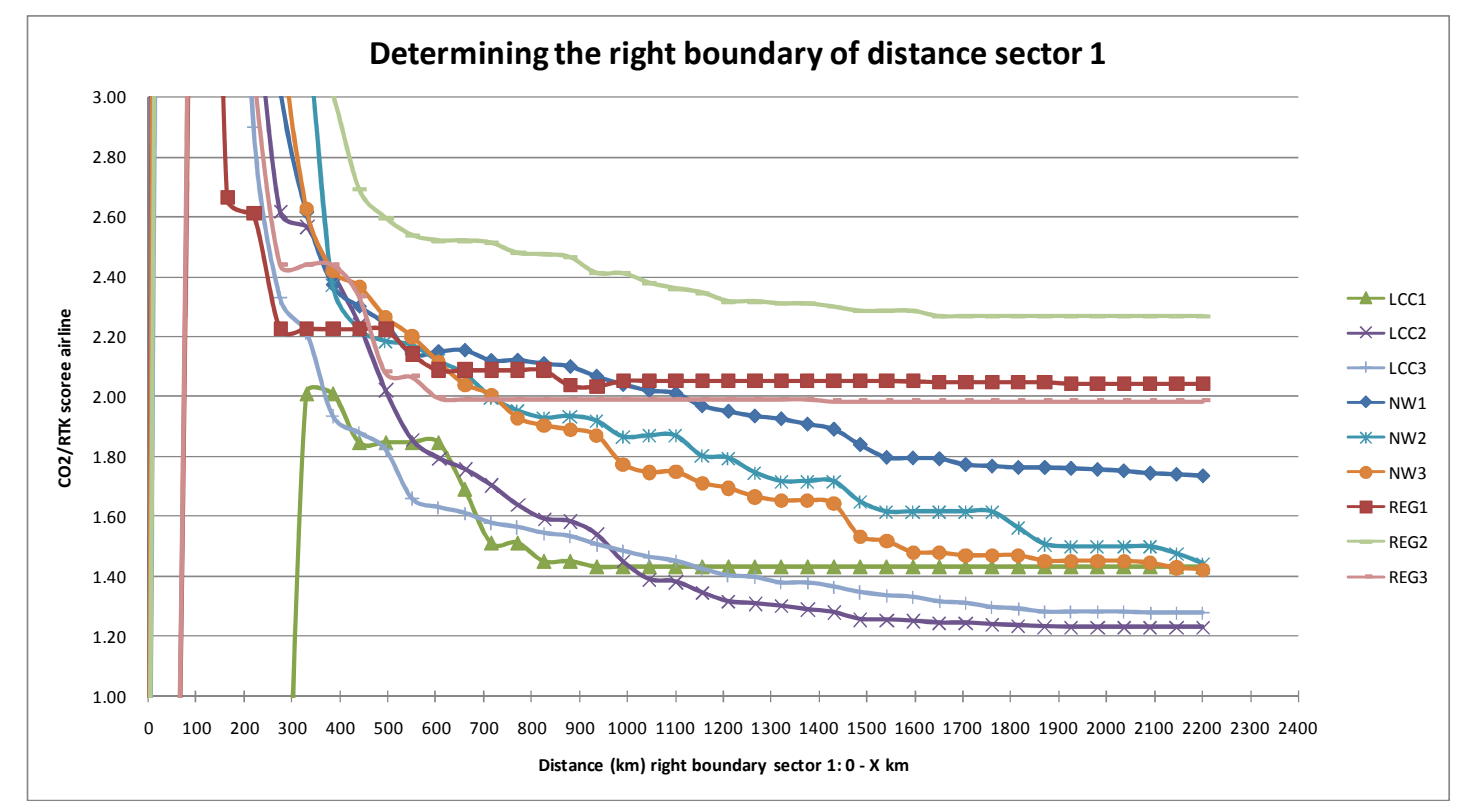

Figure 4a. CO2/ RTK score of selected airlines while extending the right boundary to determine distance sector 1.

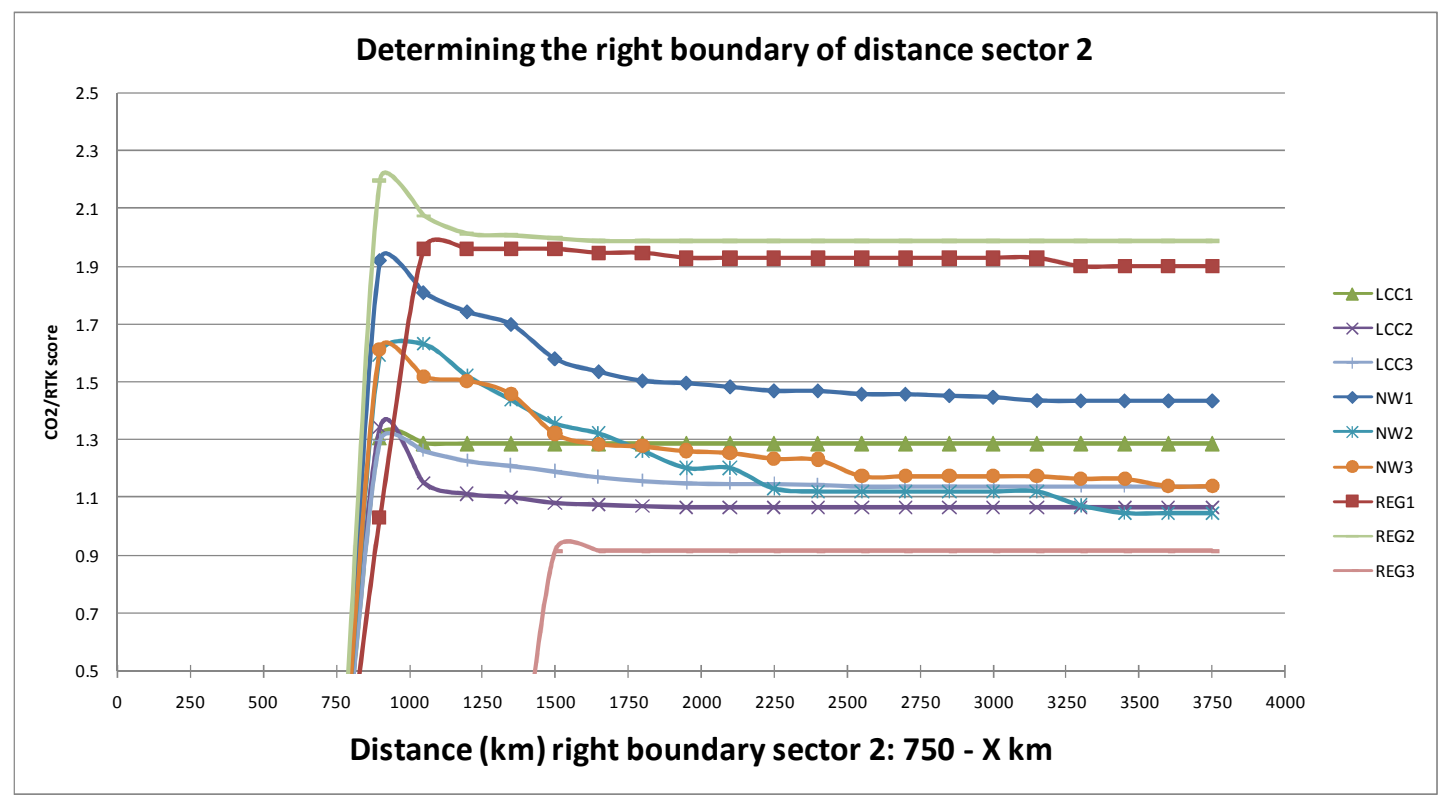

Figure 4b. CO2/RTK score of selected airlines while extending the right boundary to determine distance sector 2 . 
For the second distance sector, the left boundary is $750 \mathrm{~km}$, and the right boundary will now be determined following the same approach. Figure 4 shows the $\mathrm{CO}_{2} / \mathrm{RTK}$ score when calculating the $\mathrm{CO}_{2}$ efficiency from $750 \mathrm{~km}$ onwards. It can be seen that the position of airlines do not change anymore significantly. Due to the assumption that network airlines have a CLF of $25 \%$ from $1,500 \mathrm{~km}$ onwards, the $\mathrm{CO}_{2}$ efficiency of $\mathrm{NW}$ carriers increases after that distance. Regional carriers 1 and 2 have only few flights after about 1,500 km which can be seen by the constant $\mathrm{CO}_{2} / \mathrm{RTK}$ score. Regional carrier has only 1 route-pair at a distance above 1,500 km, which is the reason why the score starts at that distance. Four groups can be distinguished: REG1-2; NW1; LCC1-3, NW2-3; and REG3. For this distance sector it has been chosen to put the boundary at $2,000 \mathrm{~km}$. The second distance sector is thus defined as: 750-2,000 km. It should be noted that when considering more airlines these distance sectors may be chosen differently.

In a similar way, distance sector 3 has been set at 2,000-4,000 km, and distance sector 4 at 4,000 km and above. It has been decided to define only four distance sectors because adding an additional distance sector would not considerably change the relative positions of airlines with respect to the latter.

Table 3 shows the $\mathrm{CO}_{2} /$ RTK score of airlines when using the base case input data, i.e. using standardized durations and thrust settings for the LTO phase, etc. It should be mentioned that by rating airlines on distance sectors, the rating score indicates which airline has a higher $\mathrm{CO}_{2}$ efficiency score based on the flights performed by an airline within that sector. It does not tell whether an individual flight of an airline in that category is more $\mathrm{CO}_{2}$ efficient than that of a competitor, i.e. an airline might operate with some very inefficient aircraft while also operating the most efficient aircraft. The results as well as ways to map the rating score on a class score will be discussed after the sensitivity results.

Table 3. Base case $\mathrm{CO}_{2}$ / RTK rating scores on the several defined distance classes

\begin{tabular}{|l|c|c|c|c|}
\hline & Sector 1 & Sector 2 & Sector 3 & Sector 4 \\
\hline Airline & $\mathbf{0 - 7 5 0 k m}$ & $\mathbf{7 5 0 - 2 0 0 0 k m}$ & $\mathbf{2 0 0 0 - 4 0 0 0 k m}$ & 4000km > \\
\hline LCC1 & 1.51 & 1.29 & - & - \\
\hline LCC2 & 1.65 & 1.07 & - & - \\
\hline LCC3 & 1.58 & 1.15 & $0.99 *$ & $0.93^{*}$ \\
\hline NW1 & 2.12 & 1.50 & 0.88 & 0.87 \\
\hline NW2 & 1.99 & 1.20 & 0.78 & 0.86 \\
\hline NW3 & 1.99 & 1.26 & 0.92 & 1.07 \\
\hline REG1 & 2.09 & 1.93 & $0.81 *$ & - \\
\hline REG2 & 2.51 & 1.99 & - & - \\
\hline REG3 & 2.00 & $0.92 *$ & - & - \\
\hline
\end{tabular}

*: very few flights in distance sector

\section{A. Sensitivity Analysis}

The $\mathrm{CO}_{2}$ emission composition of airlines differs with respect to each other, i.e. the one airline will have a higher share of taxi- $\mathrm{CO}_{2}$ emission whereas has a higher share for the cruise phase. The consequence is that changing for example an LTO parameter will affect the rating score for the one carrier different than for the other. A sensitivity diagram shows for each carrier how a change in parameter affects the rating score. A tornado diagram shows what the effect is on the rating score when varying the parameter in a typical range.

\section{Sensitivity diagram}

A sensitivity diagram has been made for each distance sector and airline. Figure 5 shows the sensitivity diagrams for NW1 and REG1. Basically, the steeper the line, the larger the effect of changes in a parameter on the $\mathrm{CO}_{2}$ rating score. Not all the parameters affect the rating score in a distance sector, i.e. the additional distance for distances between 1,500-2,900 km is not applicable, because the distance sector is from 0-750 km.

One can conclude that the LTO phases are more sensitive to changes for REG1 than for NW1. This is because regional carriers have relatively shorter flights and thus the influence of LTO is larger. On the contrary, the cruise fuel is less sensitive to changes for REG1 than for NW1. Although not shown, the sensitivity diagrams of other distance sectors show that the rating output is becoming less sensitive to LTO parameters (including APU), whereas the cruise phase will more significantly affect the rating. This is caused by the fact that the LTO fuel share to the total gets less when the distance increases, while the cruise fuel increases. 


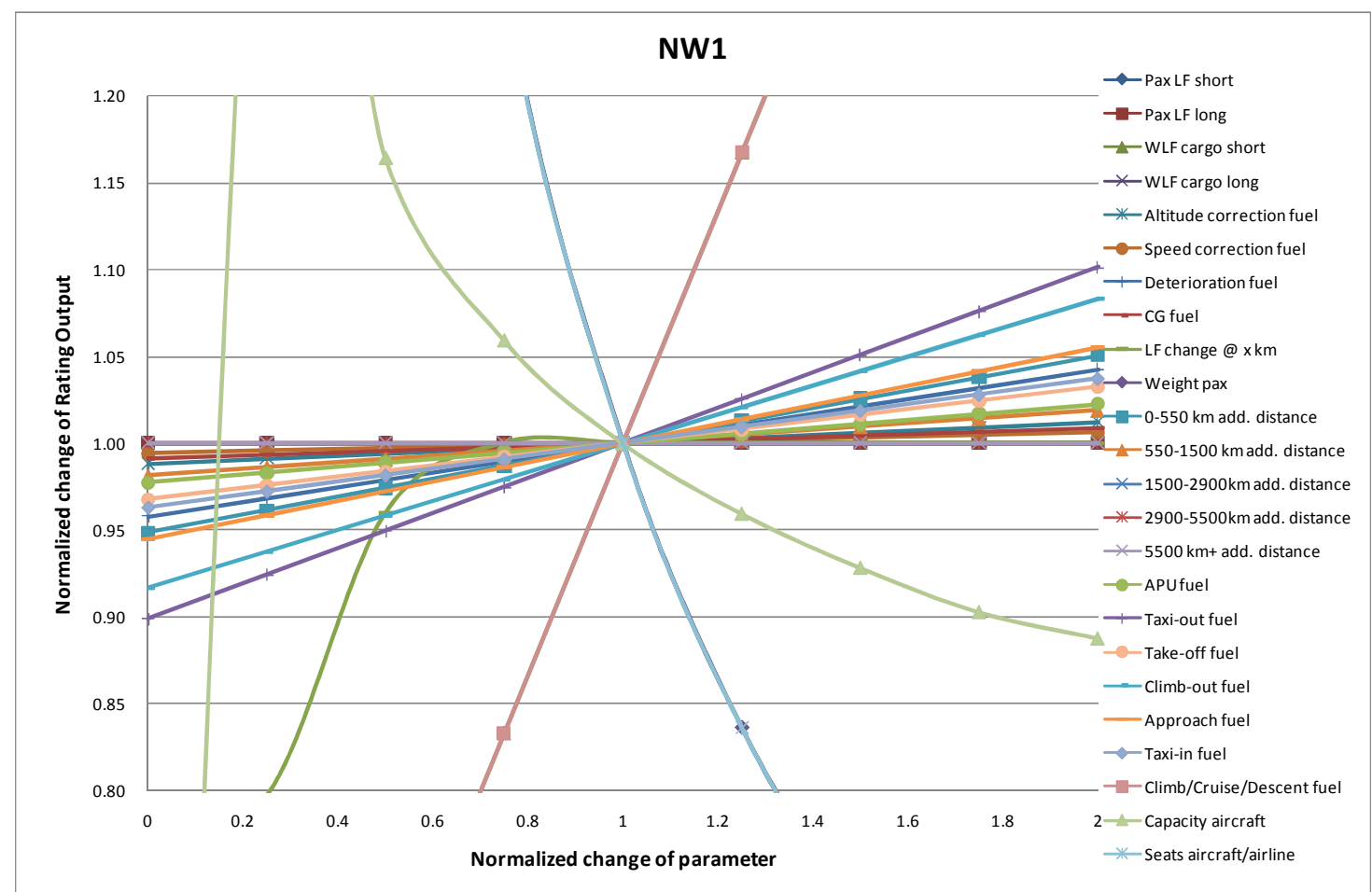

Figure 5a. The sensitivity diagram for NW1 for distance sector 1, showing what the effect is of changing a parameter (normalized) on the rating output (normalized).

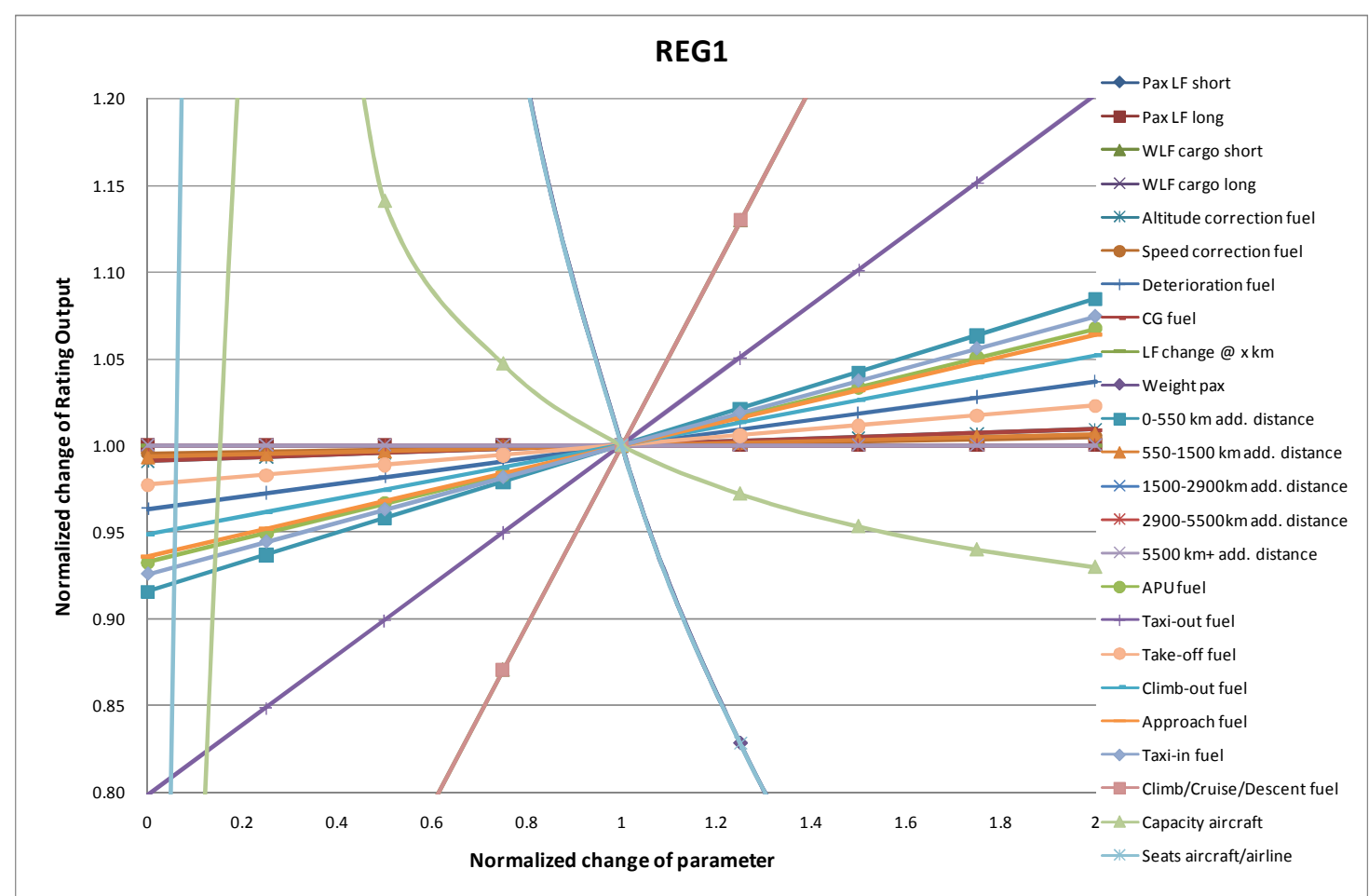

Figure 5b. The sensitivity diagram for REG1 for distance sector 1, showing what the effect is of changing a parameter (normalized) on the rating output (normalized). 
It can be seen that the parameters affecting the RTKs of an airline have all steep curves, which means that the rating output is very sensitive to changes of these parameters. This is because a change in the payload weight affecting RTK will only have a minor affect on the fuel consumption.

In the sensitivity diagram the parameters are all normalized and varied from 0-2. However, the range in which a parameter varies differs per parameter. Therefore when including these ranges, it can be deduced which parameters affect the rating the most significant, and therefore can give insight on which parameter to focus to improve accuracy of the rating.

\section{Tornado diagram}

For each parameter it has been investigated what the typical range is in which it varies. When analyzing what the effect on the rating score is of the left and right boundary of such a range, it can be determined which parameter causes the largest variance in the rating score. This is illustrated by a so-called tornado diagram, in which the parameters that most affect the rating score are on top. Figure 6 shows the tornado diagrams for NW 2 and REG 2 for distance sector 1 . It can be seen that due to uncertainty in the parameters affecting RTK's the rating score can be significantly affected. Further, the parameters affecting the LTO phase also affect the rating score considerably. From the figure it can be deduced that when a carrier has a different taxi-out time than ICAO standards, its $\mathrm{CO}_{2} /$ RTK score can be about $10 \%$ lower or $6 \%$ higher. It can be concluded that the additional distance affects the rating only slightly compared to LTO, cruise and RTK parameters. For REG carrier the influence is however higher, because additional distance flown have a relatively higher impact when the distances flown are small, i.e. the effect of $50 \mathrm{~km}$ on $200 \mathrm{~km}$ is larger than on $500 \mathrm{~km}$.

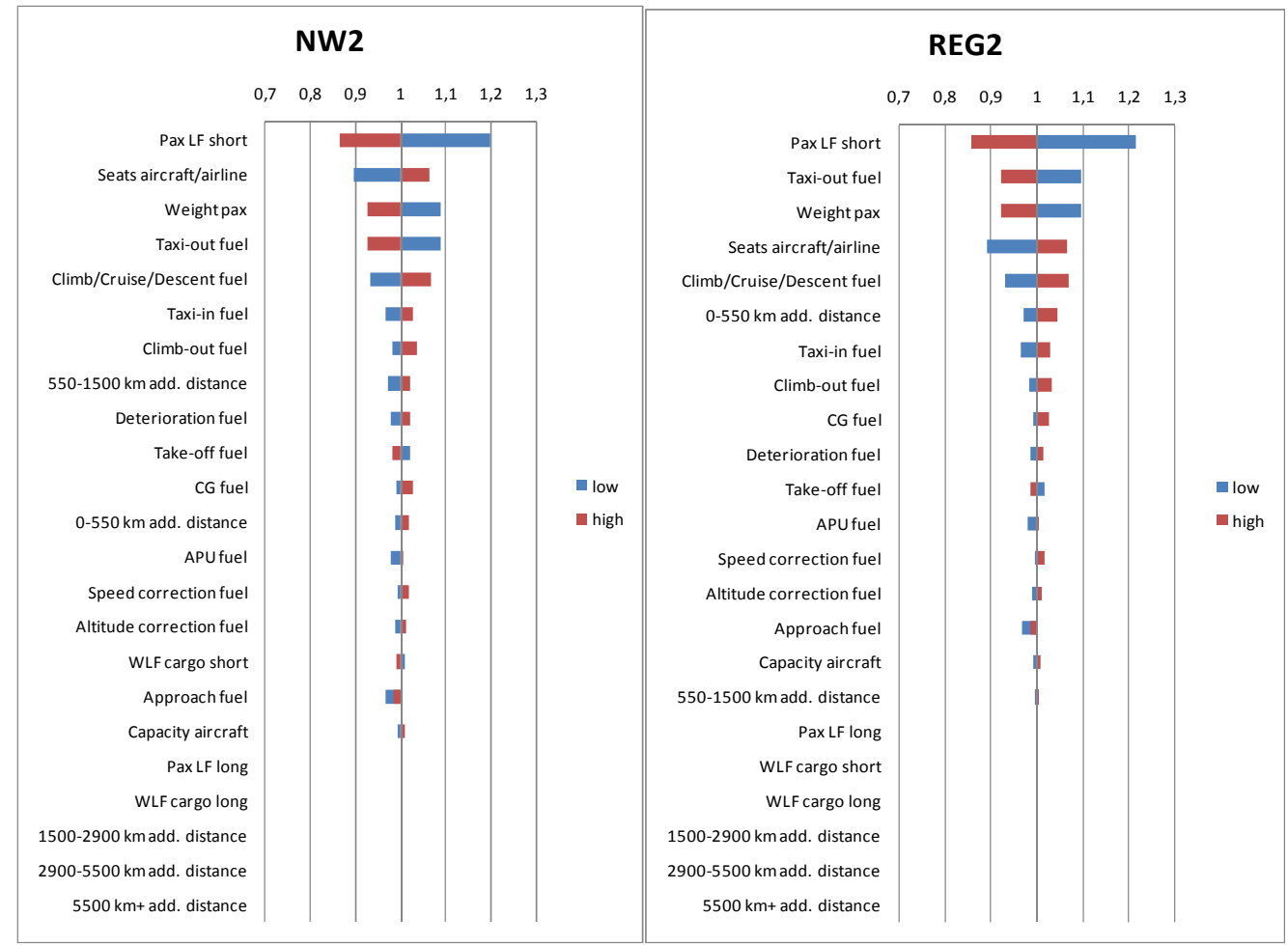

Figure 6. Tornado diagrams for a) NW-2 and b) REG-2 for distance sector 1

The total uncertainty in a $\mathrm{CO}_{2} / \mathrm{RTK}$ score has not been determined, and should be investigated in further research. Due to the uncertainty in $\mathrm{CO}_{2}$ and $\mathrm{RTK}$, from the diagrams it can be concluded that rating purely on the basis of public parameters is not possible unless the accuracy is improved of certain parameters. Without showing the tornado diagrams for the other distance sectors, it can be stated that the influence of RTK remains still significant, and that the influence of uncertainty in parameters affecting LTO get less important. On the contrary, the cruise fuel/ $\mathrm{CO}_{2}$ emission gets however more important. This difference is caused by the fact that the shares of fuel are different for the sectors. 
It can be concluded that due to uncertainty in input parameters, the $\mathrm{CO}_{2}$ efficiency of carriers may vary significantly. Therefore further research should be performed to increase the accuracy of parameters that affect the rating score significantly. Due to differences in fuel composition in distance sectors there are differences on where the focus should be in the defined sectors i.e. for distance sector 4 the cruise fuel is more important to know accurate than for sector 1, whereas for the parameters affecting LTO it is the opposite. To design a rating, in the next section the $\mathrm{CO}_{2}$ efficiency scores of airlines will be mapped on a class score.

\section{B. Rating Mapping}

When the $\mathrm{CO}_{2}$ / RTK has been determined for each airline in a distance sector, it can be mapped to a class score such as $\mathrm{A}, \mathrm{B}$, and $\mathrm{C}$. For the airline $\mathrm{CO}_{2}$ rating, it has been decided to use a similar approach as how the class scores of the EU energy labels have been determined. The base case rating scores have been determined for the considered airlines for the distance sectors (see Table 3). A linear mapping approach has been chosen to divide the airlines into 3 classes: A, B and C. The difference between the worst and best score of each distance sector (see Table 3 ) has been divided by 3 and the result has been added to the minimum $\mathrm{CO}_{2} / \mathrm{RTK}$ score. The $\mathrm{CO}_{2} / \mathrm{RTK}$ scores belonging to a class score are shown in Table 4.

Table 4. A linear approach for the rating classes

\begin{tabular}{|l|l|l|l|l|l|}
\hline & $\begin{array}{l}\text { Min } \\
\mathbf{C O}_{2} / \text { RTK }\end{array}$ & $\begin{array}{l}\text { Max } \\
\mathbf{C O}_{2} / \text { RTK }\end{array}$ & A & B & C \\
\hline Distance category 1: 0-750 km & 1.51 & 2.51 & $<1.84$ & $1.84-2.18$ & $2.18>$ \\
\hline Distance category 2: $750-2000 \mathrm{~km}$ & 0.92 & 1.99 & $<1.28$ & $1.28-1.63$ & $1.63>$ \\
\hline Distance category 3: 2000-4000 km & 0.78 & 0.99 & $<0.85$ & $0.85-0.92$ & $0.92>$ \\
\hline Distance category 4: $4000+\mathrm{km}$ & 0.85 & 1.07 & $<0.92$ & $0.92-1.00$ & $1.00>$ \\
\hline
\end{tabular}

It may be later decided to divide in more classes; however this will amongst others depend on the accuracy of the data. In analogy with $\mathrm{S} \& \mathrm{P}$, it could also be decided to rate in 3 classes and to assign a '+' or '- ' sign to the class score, i.e. A+ to show the relative standing of an airline with respect to another airline in a class,. For such relative standing, again the accuracy is important.

When the linear approach is followed, the airlines will get a class score as presented in Table 5. It should be noted that limited conclusions can be made, since the score of an airline may vary as was shown in the sensitivity analysis. When considering the base case values, LCCs have a higher $\mathrm{CO}_{2}$ efficiency than other airlines in distance sector 1, and NW carriers and REG carriers score about the same.

It can be concluded that although an airline may have a low $\mathrm{CO}_{2}$ efficiency with respect to other airlines in the one sector, it may have be better one on the other sector. When considering the base-case results, only LCC2 has an 'A' score in all sectors where it's active. Further NW2 scores 'A' on three of the four distance sectors.

Table 5. Airline ratings on the several defined distance classes

\begin{tabular}{|c|c|c|c|c|}
\hline & Sector 1 & Sector 2 & Sector 3 & Sector 4 \\
\hline Airline & 0-750km & $750-2000 \mathrm{~km}$ & $2000-4000 \mathrm{~km}$ & $4000 \mathrm{~km}>$ \\
\hline LCC1 & $\mathrm{A}$ & $\mathrm{B}$ & - & - \\
\hline LCC2 & A & A & - & - \\
\hline LCC3 & $\mathrm{A}$ & $\mathrm{A}$ & $\mathrm{C}$ & $\mathrm{B}^{*}$ \\
\hline NW1 & $\mathrm{B}$ & $\mathrm{B}$ & $\mathrm{B}$ & $\mathrm{A}$ \\
\hline NW2 & B & A & A & A \\
\hline NW3 & $\mathrm{B}$ & A & B & $\mathrm{C}$ \\
\hline REG1 & $\mathrm{B}$ & $\mathrm{C}$ & B* & - \\
\hline REG2 & $\mathrm{C}$ & $\mathrm{C}$ & - & - \\
\hline REG3 & $\mathrm{B}$ & $\mathrm{A}^{*}$ & - & - \\
\hline
\end{tabular}




\section{Conclusion}

Aviation and environment cannot be represented by $\mathrm{CO}_{2}$ emission alone. Also other environmental concerns are caused by aviation such as noise and local air quality. $\mathrm{CO}_{2}$ is seen as the main man-made greenhouse gas which induces climate change, and it is known that emitting it at the ground has the same effect as in the air. Other non$\mathrm{CO}_{2}$ GHG also play a role but the scientific knowledge about their impacts on the climate is less well known. By including non- $\mathrm{CO}_{2}$ gases, the ranking of an airline in $\mathrm{CO}_{2}$ airline rating may change. The research has scoped on the $\mathrm{CO}_{2}$ emissions which are emitted by the power source of the aircraft. When considering aviation and climate change, at the moment rating on $\mathrm{CO}_{2}$ seems appropriate given the uncertainty in impact of the other GHG on the climate.

$\mathrm{CO}_{2} / \mathrm{RTK}$ is the best ratio to express the $\mathrm{CO}_{2}$ efficiency of airlines, since it takes into account both the aircraft types as well as how aircraft use their aircraft. The ratio cannot be used directly to compare airlines in a justified way on their $\mathrm{CO}_{2}$ efficiency. Instead the $\mathrm{CO}_{2}$ / RTK needs to be determined in distance sectors.

It was shown that when considering base case values, the $\mathrm{CO}_{2}$ efficiency of an airline differs per distance sector as well as the class score, i.e. a carrier can have a low $\mathrm{CO}_{2}$ efficiency compared to other airlines on the one distance sector, whereas on the others it may have a higher score. A model was designed that estimates the $\mathrm{CO}_{2}$ emission and RTK production of airlines. However, due to lack of data availability, the $\mathrm{CO}_{2}$ emission and RTK production of an airline are difficult to estimate, i.e. it was shown that the calculated $\mathrm{CO}_{2}$ efficiency score may differ from actual. At the moment, on the basis of the data used, it is not possible to accurately determine the $\mathrm{CO}_{2} / \mathrm{RTK}$ score of an airline. Therefore, it is necessary to improve the accuracy of parameters that significantly affect the rating score.

Initial advice to airline can be given only on a high level of abstraction: an airline should strive to fill their aircraft as full as possible (either cargo or passengers), use $\mathrm{CO}_{2}$ efficient aircraft, and put aircraft on distances for which they are designed. Airlines should focus on the parameters that influence the rating the most.

\section{A. Further research and recommendations}

When one wants to rate airlines on the basis of public parameters, further research is necessary to improve the accuracy of the modeled parameters. Further research should be focused on how to improve the level of detail of the parameters that affect the rating score significantly. The accuracy of fuel and RTK estimation should be increased. The RTKs could for example be determined with more accuracy when using data from ICAO, which stores traffic by flight stage information of carriers.

Further research is necessary to decide where to place the boundaries of the distance sectors. The period on which an airline is rated should also be decided, i.e. airlines could be rated on the basis of one-month schedule, or on a yearly schedule. Since typically airlines decide in a late stadium which aircraft they put on a route, the use of data from the previous year is recommended since then the aircraft used on which route is known.

Further, it should be investigated how to introduce the rating on the market. Airlines could be given a preliminary rating score, and a verified rating score when real data is provided by the airline itself.

\section{References}

${ }^{1}$ Intergovernmental Panel on Climate Change, Aviation and the Global Atmosphere, 1999, URL: http://www.grida.no/climate/ipcc/aviation/ [cited 1 August 2008]

${ }^{2}$ ICAO, Environmental Report 2007, http://www.icao.int/icao/en/env/pubs/Env_Report_07.pdf [cited 16 July 2008]

${ }^{3}$ Ruijgrok, G.J.J. and Paassen van, D.M., Elements of aircraft pollution, Delft University Press, Delft, The Netherlands, 2007.

${ }^{4}$ Sausen et al., "Aviation radiative forcing in 2000: An update on IPCC (1999)", Meteorologische Zeitschrift, Vol. 14, No. 4, August 2005, pp. 555-561.

${ }_{5}^{5}$ Jardine, C.N., Calculating the Environmental Impact of Aviation Emissions, University of Oxford, June 2005, URL: http://www.climatecare.org/media/documents/pdf/Aviation_Emissions_\&_Offsets.pdf, [cited 10 March 2008]

${ }^{6}$ ICAO, 36th Assembly review, 2007, URL: http://www.icao.int/icao/en/jr/2007/6205 en.pdf [cited 15 August 2008]

${ }^{7}$ Faber J., Vreede G. van de, and Lee D.S., "The Impacts of the Use of Different Benchmarking Methodologies on the Initial Allocation of Emission Trading Scheme Permits to Airlines", CE Delft, Manchester Metropolitan University, July 2007, URL: http://www.ce.nl/publicatie/the impacts of the use of different benchmarking $\% 3 \mathrm{Cbr} \% 3$ Emethodologies on the initial alloc ation_of_emission_trading\%3Cbr\%3Escheme_permits_to_airlines/605?PHPSESSID=2b0c11fff16519baba0f4500597d45a9 [cited 18 August 2008]

${ }^{8}$ Air France/KLM, Corporate Social Responsibility Report 2007-08, URL: http://developpementdurable.airfrance.com/FR/fr/common/pdf/2007-08 AFKLM CSR REPORT.pdf [cited 28 August 2008]

${ }^{9} \mathrm{EU}$, "Commission Directive 95/12/EC of 23 May 1995 implementing Council Directive 92/75/EEC with regard to energy labelling of household washing machines", Eurlex online EU legislation database, URL: http://eur-lex.europa.eu/LexUriServ/ LexUriServ.do?uri=CONSLEG:1995L0012:19970117:EN:PDF [cited 4 September 2008] 
${ }^{10}$ Flybe, "Make your own Environment Label”, 2007, URL: http://www.flybe.com/pdf/eco labels make own.pdf [cited 6 August 2008]

${ }^{11}$ DeCicco, J.M., and Thomas, M., “A method for green rating of Automobiles”, Journal of Industrial Ecology, Vol. 3, 1999, pp. $55-75$.

${ }^{12}$ Standard \& Poor's, “Corporate Ratings Criteria 2006”, URL: http://www2.standardandpoor.com/spf//pdf/fixedincome/ corporateratings 052007.pdf [cited 23 June 2008]

${ }^{13}$ US Bureau of Transportation Statistics, online data library on US aviation statistics, URL: http://www.transtats.bts.gov/ [cited 18 December 2008]

${ }^{14}$ Mak B.L.M, Chan, W.W.H., Wong, K., and Zheng, C., "Comparative studies of standalone environmental reports European and Asian airlines", Transportation Research Part D 12, 2007, pp. 45-52.

${ }^{15}$ Jelinek, F., Carlier, S., and Smith, J., "Eurocontrol Experimental Centre Advanced Emission Model (AEM3) v1.5

Validation Report", EUROCONTROL, EEC Report EEC/SEE/2004/004, URL: http://www.eurocontrol.int/eec/gallery/content/ public/document/eec/report/2004/016a AEM Validation.pdf [cited 9 October 2008]

${ }^{16} \mathrm{CAA}, I C A O$ Engine Emissions Databank, URL: http://www.caa.co.uk/default.aspx?catid=702 [cited 1 November 2008]

${ }^{17}$ Unique, “Aircraft APU Emissions at Zurich Airport", 2005, URL: http://www.aero-net.org/pdf-docs/APUEmisMeth 050126.pdf [cited 10 September 2008]

${ }^{18}$ ASPIRE, 2008, http://www.airways.co.nz/ASPIRE/index.asp [cited 1 December 2008]

${ }^{19}$ Boeing, 2008, http://www.boeing.com/commercial/noise/list.html [cited 1 December 2008]

${ }^{20} \mathrm{EIG}, 2007$, (EMEP/CORINAIR) Emission Inventory Guidebook - 2007, URL: http://www.eea.europa.eu/publications/ EMEPCORINAIR3/B851vs2.4.pdf [cited 25 August 2008]

${ }^{21}$ Daggett, D.L., Sutkus Jr. D.J., DuBois D.P., and Baughcum S.L., “An Evaluation of Aircraft Emissions Inventory

Methodology by Comparisons With Reported Airline Data", NASA, URL: http://ntrs.nasa.gov/archive/nasa/casi.ntrs.nasa.gov/ 19990092373 1999123855.pdf [cited 25 August 2008]

${ }^{22}$ Airbus, "Getting to grips with fuel economy", 2004, URL: http://www.iata.org/NR/ContentConnector/CS2000/

Siteinterface/sites/whatwedo/file/Airbus_Fuel_Economy_Material.pdf [cited 1 September 2008]

${ }^{23}$ Airbus, "Getting grips with the cost index", 1998, issue II, http://www.iata.org/NR/ContentConnector/CS2000/

Siteinterface/sites/whatwedo/file/Airbus Cost Index Material.pdf [cited 1 September 2008]

${ }^{24}$ Eyers, C.J. et al, “AERO2k Global Aviation Emissions Inventories for 2002 and 2025”, QINETIQ/04/01113, 2004, URL: http://www.aero-net.org/pdf-docs/AERO2K_Global_Aviation_Emissions_Inventories_for_2002_and_2025.pdf [cited 16 July $2008]$

${ }^{25}$ Roberson, B. "Fuel Conservation Strategies: Cost Index Explained", BOEING, 2007, URL:

http://www.boeing.com/commercial/aeromagazine/articles/qtr_2_07/AERO_Q207_article5.pdf [cited 31 July 2008]

${ }^{26}$ University of Westminster, "Evaluating the true cost to airlines of one minute of airborne or ground delay", 2004, http://www.eurocontrol.int/prc/gallery/content/public/Docs/cost of delay.pdf [cited 21 March 2008]

${ }^{27}$ Kettunen, T., Hustache J.C., Fuller, I., Dowell H., Bonn J., Knorr, D., "Flight efficiency studies in Europe and the United States", Eurocontrol ATM Seminar 2005, URL: http://atm-seminar-2000.eurocontrol.fr/past-seminars/6th-seminar-baltimore-mdusa-june-2005/papers/paper 055 [cited 1 September 2008]

${ }^{28}$ Faber, J., and Nelissen, D., "Indelingen van vliegtuigtypen in milieuklassen: Verslag voor de werkgroep differentiatie vliegbelasting", May 2008, URL: www.ce.nl/?go=home.downloadPub\&id=807 [cited 1 August 2008]

${ }^{29}$ Hutter, I, "Engine Deterioration and Maintenance Actions", General Electric Aviation, presentation at ICAO Transport Canada Conference Aircraft Panel, Montreal, URL: http://www.icao.int/env/WorkshopFuelEmissions/Presentations/Hutter.pdf [cited 1 August 2008]

${ }^{30}$ Eurocontrol, "Eurocontrol Experimental Centre: Study of the acquisition of data from aircraft operators, to aid trajectory prediction calculation", 1998, URL: http://www.eurocontrol.int/eec/gallery/content/public/document/eec/report/1998/ 028 Data to Aid Trajectory Prediction Calculation.pdf [cited 26 November 2008]

${ }^{31}$ Seatguru, http://www.seatguru.com, [cited 5 December 2008]

${ }^{32}$ Airfleets.net, http://www.airfleets.net, [cited 6 December 2008] 